\title{
甘erlandlungen
}

Dอร

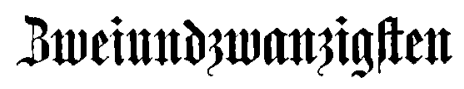

\section{Dentlden $\mathfrak{I} \mathfrak{u}$ riftentages.}

Şerausgegeben

von

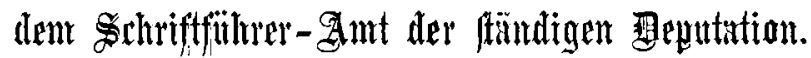

Gintadjten.

(E) $\mathfrak{i} \mathfrak{f} \mathfrak{e} \mathfrak{\mathfrak { r }} \mathfrak{B} \mathfrak{a} \mathfrak{n} \mathfrak{d}$.

Werlin.

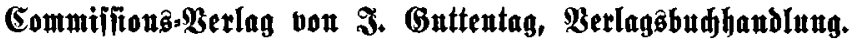
1892. 
